DIW BERLIN

Discussion

Papers

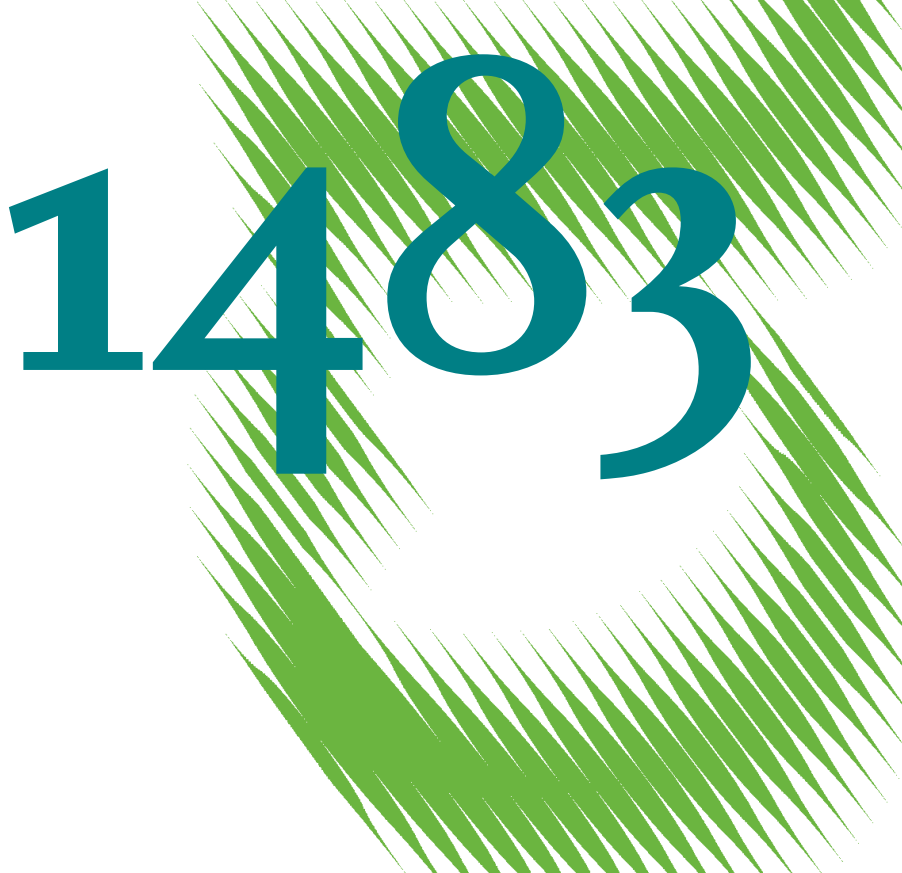

Modelling a Market Stability

Reserve in Carbon Markets

Anne Schopp, William Acworth, Daniel Huppmann and Karsten Neuhoff 
Opinions expressed in this paper are those of the author(s) and do not necessarily reflect views of the institute.

IMPRESSUM

(C) DIW Berlin, 2015

DIW Berlin

German Institute for Economic Research

Mohrenstr. 58

10117 Berlin

Tel. +49 (30) $89789-0$

Fax +49 (30) $89789-200$

http://www.diw.de

ISSN electronic edition 1619-4535

Papers can be downloaded free of charge from the DIW Berlin website:

http://www.diw.de/discussionpapers

Discussion Papers of DIW Berlin are indexed in RePEc and SSRN:

http://ideas.repec.org/s/diw/diwwpp.html

http://www.ssrn.com/link/DIW-Berlin-German-Inst-Econ-Res.html 


\title{
Modelling a market stability reserve in carbon markets
}

\author{
Anne Schopp ${ }^{a}$, William Acworth ${ }^{a}$, Daniel Huppmann ${ }^{a, b}$, Karsten Neuhoff $^{a, c, d}$
}

May 2015

We examine under which conditions a cap-and-trade mechanism can deliver a dynamically efficient abatement pathway and contribute to a robust investment framework. For this we develop a numerical dynamic partial-equilibrium model that includes differentiated objective functions of different market participants for holding emission allowances based on their banking strategy. If the surplus of allowances is large, as currently observed in the European Union Emissions Trading System, the equilibrium market outcome can deviate from an efficient abatement pathway and performance of the policy is reduced against a set of key criteria (dynamic efficiency, price credibility, price consistency, and robustness to shocks). The model is applied to assess design options of quantity and price based market stability reserves as discussed in Europe. Both price and quantity based mechanisms can improve the performance of the EU ETS against key criteria.

JEL Codes: D84, G18, Q48

Keywords: Computational Model, Emissions trading, Environmental Regulation, Market stability reserve

Acknowledgement: We are grateful for financial support from Stiftung Mercator for a model comparison exercise on the Market Stability Reserve and to the EUREEM project funded by the German Federal Ministry for Economic Affairs and Energy (BMWi).

\footnotetext{
${ }^{a}$ German Institute for Economic Research, Mohrenstrasse 58, 10117 Berlin, Germany

${ }^{b}$ Department of Civil Engineering, Johns Hopkins University, 3400 N. Charles St., Baltimore, MD 21218, USA

${ }^{c}$ Faculty of Economics and Management, Technical University Berlin, Straße des 17. Juni 135, 10623 Berlin, Germany

${ }^{d}$ Corresponding author: Karsten Neuhoff, Email: kneuhoff@diw.de, Tel. 0049(0)30 89789470
} 


\section{Introduction}

Cap-and-trade schemes provide flexibility to realize emission reductions - both by trading between firms and by banking of allowances between years. As such, the mechanism not only supports the realization of efficient mitigation options across different sources, but also the efficient timing of mitigation options to deliver an efficient abatement pathway (Chevallier, 2012; Rubin, 1996). Thus, static efficiency can be achieved despite an inherently crude initial allocation of emission allowances to installations. Also dynamic efficiency can be achieved despite inherently simplified trajectories for the emission cap determined through political processes.

However, market imperfections can result in deviations from an efficient outcome. Transaction costs can limit trade between firms and hence reduce static efficiency (Stavins, 1995). Uncertainty about abatement costs and risk aversion can yield inefficient investment levels in low carbon technologies and thus reduce dynamic efficiency (Baldursson and Von der Fehr, 2004). We examine a further factor that may result in deviations from the efficient abatement pathway. Because of market and regulatory risks, speculative investors require a high risk premium for holding $\mathrm{CO}_{2}$ allowances or derivative contracts (Bessembinder, 1992; Wang, 2001). This is not of concern, if the surplus of allowances is limited and used by market participants to hedge their production costs in future years. However, if the surplus of allowances exceeds hedging volumes, then today's carbon price declines compared to the carbon price to be expected in future years until the return requirements are sufficiently attractive for speculative investors. Such a carbon price trajectory exceeding the social discount rate may no longer result in dynamically efficient operational and investment choices (Neuhoff et al., 2012).

In the European Union Emissions Trading System (EU ETS) a surplus of allowances has accumulated which is bigger than the volume of annual emissions of the covered installations. This surplus results from a larger inflow of international off-set credits than anticipated, but also from lower than expected emissions due to the economic crisis. With the surplus of allowances the carbon price dropped from previous heights of $30 \mathrm{Euro} / \mathrm{tCO}_{2}$ to levels below $5 \mathrm{Euro} / \mathrm{tCO}_{2}$. This has been argued to be insufficient to facilitate investments seen to be necessary to achieve longer-term emission mitigation targets (dynamic efficiency) and has raised questions on the commitment of European policy makers to climate objectives.

Hence, in January 2014 the European Commission proposed a Market Stability Reserve (MSR) to reduce the surplus of allowances in the market. The MSR proposal has been endorsed by the European Council (EU, 2014a). A share of allowances that would otherwise be auctioned to market participants are stored in the reserve if the surplus exceeds an upper trigger levels (EU, 2014b). If the surplus was to fall below a predefined lower trigger, then some allowances are released from the reserve.

From a theoretical perspective, removing allowances temporarily from the market through a MSR substitutes private banking by market participants. In the absence of any market or regulatory failures, the substitution of public for private banking through a MSR should not impact long term 
prices and abatement decisions. However, if market or regulatory failures are considered, then this result might no longer hold.

We model the implications of a limited capacity of power and industry firms to bank allowances beyond hedging needs at social discount rates. Thus, the additional surplus is to be banked as speculative investment with high return requirements linked to market and regulatory risk. The novelty of the model is that it represents different banking strategies: hedging for the purpose of compliance and speculation as an investment in buying or selling allowances if the expected returns meet return requirements for the capital employed. Using a dynamic, deterministic partialequilibrium framework, we first assess the performance of the EU ETS without an MSR and then assess different MSR design choices. We develop a set of four indicators that are quantified through our modelling approach: dynamic efficiency, price credibility, price consistency, and robustness to shocks.

We find that under conditions of excessive surplus, constraints on banking at social discount rates result in deviations from an efficient abatement pathway. MSR designs can compensate for this market or regulatory failure to different degrees. A quantity based MSR, as proposed by the European Commission, provides additional flexibility through publicly banking surplus allowances, thus incentivizing higher abatement levels early on and shifting firms' abatement profiles closer to the optimal abatement cost pathway. The MSR reduces the slope of the carbon price trajectory. Furthermore, the MSR increases the inter-temporal flexibility of the EU ETS making it more responsive and robust to exogenous shocks.

Variations to the MSR design can improve on the European Commission's proposal: a mechanism that starts earlier and places the back-loaded allowances directly into the reserve increases the performance of the EU ETS, particularly over the next decade, compared to the European Commission's approach. In addition, increasing the response rate as well as the speed of the reserve to react to unforeseen shocks within one instead of two years can increase robustness and dynamic efficiency. The choice of the trigger levels across MSR designs is non-trivial. If trigger levels are set too high the MSR will be ineffective, if they are set too low they can create some volatility. As such, monitoring of the hedging demand is recommended and trigger levels should be updated based on evolving hedging requirements.

The analysis of price based reserves shows that they perform best, if the lower price level is set at a sufficiently high level that approximates the marginal abatement cost curve. The latter finding is in line with previous studies on hybrid cap-and-trade schemes (Fell, 2015; Fell and Morgenstern, 2010; Stranlund et al., 2014).

The remainder of the paper is structured as follows. Section 2 outlines a framework to assess emission permit markets and MSR designs. Section 3 outlines the model before section 4 presents the data. Section 5 discusses the results and tests their sensitivity. Section 6 concludes.

\section{Evaluation framework}

The EU ETS was implemented to facilitate trading across installations and through time, so as to reduce the cost of climate policy by first adopting lower cost abatement options. By setting targets 
and allowing the market to drive abatement decisions, the EU ETS promised to overcome concerns surrounding the time inconsistency of the short-term policy commitments and provide a credible framework for private sector investors. Criteria to assess whether these objectives have been (or will be) addressed are outlined in the points below.

The dynamically efficient abatement pathway refers to inter-temporal optimisation. Key to the proper functioning of a cap-and-trade system is the banking of allowances by market participants that provides flexibility for the distribution of abatement through time. Thus, the net present value of abatement cost can be reduced, while the politically agreed emission trajectory is not violated. Dynamic efficiency is measured by the net present value of the abatement $c_{t}$ for all periods using the social discount rate $r_{\text {social }}$. To avoid distortions from end of period effects we account for permits in the reserve, $R_{T}$, in the final period $T$. They are valued at the average discounted permit price, $p_{t}$ in the last $L$ periods. This allows for comparability across scenarios with differing reserve volumes at the end of the modelling horizon. The ranking of the different MSR options across the models was largely robust to variations of $L$, results are presented for $L=20$.

$$
\text { Efficiency }=\sum_{t=1}^{T} \frac{c_{t}}{\left(1+r_{\text {social }}\right)^{t}}-R_{T} \sum_{T-L}^{T} \frac{1}{L+1} \frac{p_{t}}{\left(1+r_{\text {social }}\right)^{t}}
$$

Price Credibility and Price Consistency are crucial to enable cap-and-trade systems to steer capital towards low carbon investments and innovations. Investors lack robust evidence about the carbon price level to be expected in future years. In particular, they lack evidence that future governments will demonstrate a stronger commitment to carbon pricing than today's government. Hence, investors might struggle to believe that future carbon prices will be far higher than today's carbon price. We therefore consider price credibility to reflect the alignment of today's spot price with the carbon price that is relevant during the years over which investors will recover their investment costs. We approximate this carbon price credibility by the average slope of the carbon price trajectory.

$$
\text { Credibility }=\sum_{t=1}^{T} \frac{1}{T} \min \left(\mid \frac{p_{t+1}-p_{t}}{p_{t}}, M\right)
$$

In periods of prices close to zero, small price increases can translate into large slopes that would dominate the result. Hence, a cut-off value $M$ for the maximum slope to be considered is introduced (results for $M=0.2$ are presented).

To measure Price Consistency we compare the forward price $p_{t}^{F}$ for the carbon price in $F$ years with the price later realized.

$$
\text { Consistency }=\sum_{t=1}^{T-F} \frac{1}{T-F}\left|\frac{p_{t+F}-p_{t}^{F}}{p_{t+F}}\right|^{1 / 10}
$$

Robustness to shocks is a repeated concern voiced about carbon markets. This is because price volatility in pure quantity based carbon markets may be excessive as the supply for carbon permits is fixed and therefore unable to respond to changes in price. As such, external shocks like from a recession or unexpected technological progress can have strong price effects. Allowing flexibility about the timing of emission reductions improves the robustness of a cap-and-trade system as the impacts of the shock are spread through time, reducing price volatility and improving welfare. Robustness of the EU ETS to exogenous shocks is measured by assessing how the efficiency indicator 
changes in response to the shock and compared to the change of the efficiency indicator in an optimal response to the shock.

To assess the EU ETS and compare MSR design options, these performance indicators are set within a scale determined by two hypothetical extremes. First, no market failures such that the price path follows a social discount rate (representing a score of 100) and second, zero inter-temporal optimisation such that prices are dictated by annual demand supply balances (representing a score of zero). For further details regarding the scaling method see Neuhoff et al. (2015).

\section{Model}

The banking of $\mathrm{CO}_{2}$ allowances in cap-and-trade schemes allows surplus allowances to be transferred to future years. There are three underlying motives explaining the banking of allowances, according to Bailey's (2005) analysis of financial markets: hedging, speculation, and arbitrage. Hedgers buy or sell commodities and forward contracts in order to protect against input or product price changes. Speculators buy or sell commodities and forward contracts as an investment that meets their riskreturn requirements. Arbitrageurs aim to benefit from price differentials between spot and forward prices.

Hedging in the EU ETS is mainly pursued by power firms. Power firms sell a significant share of their power one to three years ahead of delivery. Corporate risk management requires that contracts for fuel and carbon input are signed in parallel. This creates hedging needs for carbon emissions. Based on statistical analysis and interviews with market participants, Neuhoff et al. (2012) find that power firms are the main actor holding surplus allowances in order to hedge emissions from electricity production sold on forward contracts. Due to internally established risk management requirements power firms typically have limited capacity to bank beyond their hedging needs. Thus, any additional surplus requires market participants that acquire allowances not for hedging but as speculative investment.

Speculation can be pursued over both the short and long-term. Over short-term periods of hours or sometimes days, market participants have continuously pursued small-scale speculative investments in emission allowances to arbitrage price changes, thus, providing liquidity and reducing short-term fluctuations in the carbon price. However, given the inherent risk in commodity markets amplified with regulatory risk and uncertainty, market participants require significant risk premiums to invest in $\mathrm{CO}_{2}$ allowances. For example, it was reported that financial investors would, in principle, only be prepared to pursue speculative investments in carbon if annual rates of return exceeded $10-15 \%$ (Neuhoff et al., 2012). As such, they would only acquire allowances if spot prices are sufficiently low compared to their expectations about the price in later years so as to allow for an expected annual price increase exceeding $10-15 \%$. This is consistent with analyses of hedging pressures in other commodity markets. Empirical analyses suggest that investors require annual returns in excess of $10 \%$ for bearing the risk in various commodity markets (Bessembinder, 1992; Wang, 2001). ${ }^{1}$

\footnotetext{
${ }^{1}$ Emission allowances - apart from zero storage costs - have features in common with many other commodities. This means that financial contracts on the carbon price can be compared to similar commodity contracts in terms of risk exposure and trading liquidity.
} 
Arbitrage is often pursued by banks. As allowances can be banked at zero cost, banks can acquire emission allowances, and sell forward contracts (for example to power firms), thus avoiding price risk while recouping their cost of capital. Banks constitute the biggest buyer of European Emission Allowances (EUAs) (Betz et al., 2015). They and other financial actors often buy allowances from industry or auctions and sell forward or future contracts to power firms. In turn, power firms use these contracts to hedge forward sales of power. They acquire forward and future contracts rather than using EUAs to improve their cash position and because their internal capital costs are higher than the capital costs of banks (Betz et al., 2015). In fact, in the second trading period future contracts were generally traded 3-4 years ahead with a premium of about 3-5\% per year (EEX, 2012). As long as continuity of the $\mathrm{CO}_{2}$ allowances is guaranteed and thus regulatory risk for arbitrage is avoided, the forward curve for $\mathrm{CO}_{2}$ allowances will not increase at a steeper rate.

This does not imply that market participants might not hold expectations that the carbon price will increase at a steeper rate. Simplified models assume that differences between price expectations and future prices are arbitraged away. However, to pursue this arbitrage the market participant will be exposed to the carbon price risk of holding an open position. This would be a speculative investment that will only be pursued if the return on capital employed to secure the open position is high enough. Thus, it will be only pursued once the difference between the future price and the expected price exceeds $10-15 \%$ per year. Hence, it is perceivable that price expectations differ from prices at which future contracts are traded.

In the following we introduce a dynamic, deterministic partial-equilibrium model representing hedging and speculation in a typical model of a cap-and-trade system with annual abatement decisions by emitters. The activities of arbitrageurs are implicitly modelled, by assuming that hedgers directly acquire spot allowances instead of acquiring future contracts from arbitrageurs that in turn buy spot allowances.

\section{Emissions}

The representative emitter produces industrial and power sector emissions $y_{t}$ in year $t$ in absence of abatement efforts. The emitter can abate emissions, $x_{t}$, according to a linear marginal abatement cost function with intercept $\vartheta_{t}$ and slope $m_{t} .{ }^{2}$ For the remaining emissions the allowance price $p_{t}$ has to be paid, which arises out of the market clearing condition in each time period.

The emitter's profit maximization problem can be solved using its first-order optimality (or KarushKuhn-Tucker, KKT) condition:

$$
0 \leq \beta^{t-1}\left[-p_{t}+\vartheta_{t}+m_{t} x_{t}\right] \perp x_{t} \geq 0 \quad \forall t
$$

Equation 5 stipulates the familiar result that abatement is carried out as long as the marginal cost of an additional unit of emission reduction is below the allowance price.

\footnotetext{
${ }^{2}$ A quadratic marginal abatement cost curve is also tested in the sensitivity analysis.
} 


\section{Hedging}

The hedger represents conventional (fossil fuel-based) power firms that sell power several years ahead of production in order to reduce exposure to price risks and profit volatility from power production. Following internal risk management procedures, at the time of selling power firms also acquire the input factors for the power production, namely coal, gas, and carbon emission allowances or contracts on these inputs. Hedging by European power firms is a firm specific corporate strategy decision. Interviews with European power firms reveal that firms prefer to hedge uniformly across the portfolio of their generation assets rather than hedging with a strong emphasis on one specific generation technology. Therefore, they acquire in parallel to the power sale contracts for the inputs in proportion to their generation portfolio (hedging schedule). The amount of allowances bought in year $t$ to hedge exposure in the subsequent year is denoted by $h_{t}$. Traders in the power firms have some flexibility (hedging flexibility) to deviate from this hedging schedule in order to exploit market price differentials. Thus, if power firms expect the carbon price to be significantly higher than the price at which futures are traded, they will increase their hedging volume. Yet this flexibility is restricted by institutional constraints, thus creating a hedging corridor, which defines the upper and lower limits of hedging demand (Schopp and Neuhoff, 2013).

In our simple model the hedging schedule fixes the hedged percentage $\gamma_{t}$ of the power generation from coal $C_{t}$ and natural gas $G_{t}$. The resulting demand for emission allowances depends on the carbon intensity of the fuels, denoted by $i_{c}$ and $i_{g}$, respectively. The flexibility to deviate from this hedging schedule is represented by the parameter $\alpha$. Power firms hedge more than specified in their hedging schedule, if they expect carbon prices $p_{t+1}$ to increase at a higher rate than the rate $\delta^{m}$ at which forwards contracts are traded, and vice versa.

The hedger's first-order optimality condition is given as follows:

$$
0 \leq \beta^{t-1}\left[h_{t}-\gamma_{t}\left(C_{t} i_{c}+G_{t} i_{g}\right)\left(1+\alpha\left(\frac{p_{t+1}}{p_{t}}-\left(1+\delta^{m}\right)\right)\right)\right] \perp h_{t} \geq 0 \quad \forall t
$$

\section{Speculation}

Speculators bank allowances, $s_{t}$, not with the aim of hedging any future emissions, but to make profit by betting that the carbon price will develop in a certain way. They take such an open position, if they expect the price increase over the next year to be greater than their annual required rate of return, $\delta_{s}$. We assume new speculators enter the market as long as returns exceed this threshold level.

The speculator's first-order optimality condition is given by:

$$
0 \leq \beta^{t-1}\left[-p_{t+1}+p_{t}\left(1+\delta_{s}\right)\right] \perp s_{t} \geq 0 \quad \forall t
$$

\section{Market clearing}

The market for emission allowances must clear in each period. The supply of allowances is given by the amount of allocated allowances under the EU ETS cap and the import of offsets, $a_{t}$, as well as the banked allowances of previous years, $h_{t-1}+s_{t-1}$. Demand for allowances results from net emissions, 
$y_{t}-x_{t}$, and the banking volumes of hedgers and speculators, $h_{t}+s_{t}$. In addition, for those scenarios where an MSR has been implemented, allowances are withdrawn from or released to the market by the reserve, $r_{t}$.

The market clearing condition is formulated as:

$$
0 \leq a_{t}-r_{t}-\left(\left(y_{t}-x_{t}\right)+h_{t}+s_{t}\right)+h_{t-1}+s_{t-1} \perp p_{t} \geq 0 \quad \forall t
$$

The treatment of banking demand in the final modelling period requires specific consideration. Since there is no price beyond the final period, KKT conditions would imply that both banking and hedging volumes are zero. We do not expect to observe the large price increases necessary to warrant speculative investment in the final periods. As a consequence, not having speculative banking in the final period $\left(s_{T}=0\right)$ as it is implied by the KKT condition, is a sensible result in our framework. The situation is different, however, with regard to hedging. We solve this problem by fixing hedging and private banking in the final period at the level of the previous period: $h_{T}=h_{T-1} .^{3}$.

The endogenous variables and exogenous parameters are summarized in Table 1. Each participant's profit maximization problem is linear or concave quadratic; therefore the first-order optimality conditions of the emitter, hedger and speculator result in a unique equilibrium. They are solved simultaneously, combined with the market clearing constraint for each period, to find a simultaneous-move, open-loop Nash equilibrium. Mathematically, this yields a Mixed Complementarity Problem (MCP), which is implemented in GAMS and solved using the PATH solver.

\footnotetext{
${ }^{3}$ This assumption implies that the variables related to hedging in the market clearing constraint are omitted in the last year of the model horizon.
} 
Table 1: Model variables and parameters

\begin{tabular}{|c|c|c|}
\hline Variables & Description & Unit \\
\hline$x_{t}$ & Abatement in year $\mathrm{t}$ & $\mathrm{GtCO}_{2}$ \\
\hline$h_{t}$ & Hedging volume by power sector in year $t$ & $\mathrm{GtCO}_{2}$ \\
\hline$s_{t}$ & Banked allowances by speculators in year $\mathrm{t}$ & $\mathrm{GtCO}_{2}$ \\
\hline$p_{t}$ & Carbon price in year $t$ & $\mathrm{EUR} / \mathrm{tCO}_{2}$ \\
\hline$r_{t}$ & Allowances withdrawn or released from market in year $\mathrm{t}$ & $\mathrm{GtCO}_{2}$ \\
\hline Parameters & Description & Unit \\
\hline$\beta$ & Discount factor & \\
\hline$a_{t}$ & Allocated allowances and imported offsets in year $t$ & $\mathrm{GtCO}_{2}$ \\
\hline$y_{t}$ & Emissions in absence of abatement in year $t$ & $\mathrm{GtCO}_{2}$ \\
\hline$m_{t}$ & Abatement cost slope parameter in year $\mathrm{t}$ & $\mathrm{EUR} /\left(\mathrm{tCO}_{2} * \mathrm{GtCO}_{2}\right)$ \\
\hline$\vartheta_{t}$ & Abatement cost intercept in year $\mathrm{t}$ & $\mathrm{EUR} / \mathrm{tCO}_{2}$ \\
\hline$i_{c}$ & Carbon intensity of coal & $\mathrm{GtCO}_{2} / \mathrm{TWh}$ \\
\hline$i_{g}$ & Carbon intensity of gas & $\mathrm{GtCO}_{2} / \mathrm{TWh}$ \\
\hline$\gamma_{t}$ & Hedged percentage in year $\mathrm{t}$ & \\
\hline$C_{t}$ & Coal power generation in year $\mathrm{t}$ & TWh \\
\hline$G_{t}$ & Gas power generation in year $\mathrm{t}$ & TWh \\
\hline$\delta^{s}$ & Required rate of return per year by speculators & \\
\hline$\delta^{m}$ & Market rate of return per year & \\
\hline$\alpha$ & Hedging flexibility parameter & \\
\hline
\end{tabular}

\section{Modelling reserves}

There are two main approaches to implement public allowance banking in a cap-and-trade system with so called MSRs: either based on quantity or on price based triggers that activate publicly controlled reserves. We assess design options of both quantity and price based reserves. In particular, we assess four MSRs, including: (i) the European Commission proposal (EC MSR); (ii) the British/German proposal (Early Start MSR); (iii) the French Government proposed MSR (High Inj MSR) and (iv) a Price Based MSR with two different price triggers.

The European Commission proposed the introduction of a MSR from 2021. According to the proposal this reserve is activated if the Allowances in Circulation ${ }^{4}, A i C_{t}=\sum_{t}\left[a_{t}-r_{t}-\left(y_{t}-x_{t}\right)\right]$, move outside the quantity corridor of $0.4-0.833 \mathrm{GtCO}_{2}$. The withdrawal is set at $12 \%$ of $\mathrm{AiC}_{t}$ and the injection is set at $0.1 \mathrm{GtCO}_{2}$. The reserve reacts with a two year delay to the allowances in circulation. We implement the upper and lower quantity triggers as follows:

\footnotetext{
${ }^{4}$ Allowances in circulation are the cumulative number of allowances issued in the period since 1 January 2008 and entitlements to use international credits exercised by installations under the EU emission trading system in respect of emissions up to 31 December of year $\mathrm{x}$, minus the cumulative tonnes of verified emissions from installations under the EU emission trading system between 1 January 2008 and 31 December of year $x$, any allowances cancelled in accordance with Article 12(4) of Directive 2003/87/EC and the number of allowances in the reserve (Commission 2014).
} 


$$
\begin{aligned}
& \text { If } \mathrm{AiC}_{t-2}>0.833 \mathrm{GtCO}_{2} \text {, then } r_{t}=0.12 * A i C_{t-2} \\
& \text { If } \mathrm{AiC}_{t-2}<0.4 \mathrm{GtCO}_{2} \text {, then } r_{t}=-0.1
\end{aligned}
$$

The MSR proposed by the United Kingdom and Germany (Early Start MSR) starts earlier (2017) and receives the $0.9 \mathrm{GtCO}_{2}$ back-loaded allowances.

France proposed symmetric withdrawal and injection at a rate of $33 \%$ of the difference between the allowances in circulation and the corridor. The corridor is initially set at 0.8-1.3 $\mathrm{GtCO}_{2}$ but reviewed more frequently than the five years envisaged in the EC MSR (DGEC, 2014). A one rather than two year delay is proposed. We label this as High Inj MSR and formulate it as:

$$
\begin{gathered}
\text { If } A i C_{t-1}>1.3 \text {, then } r_{t}=0.33\left(A i C_{t-1}-0.8\right) \\
\text { If } A i C_{t-1}<0.8 \text {, then } r_{t}=-0.33\left(1.3-A i C_{t-1}\right)
\end{gathered}
$$

Finally, we model a Price Based MSR with two levels of reserve prices for auctions: 10 Euro and 20 Euro in 2021, both increasing at 5\% each year. Allowances from the MSR are returned to the market at a separate price trigger (so called soft price cap) (Clò et al., 2013).

We implement the MSRs by iterative calculation of an emission and price profile with the Mixed Complementarity Problem (MCP) and the determination of allowances moved in and out of the MSR based on the profile. The result is converging for all the results presented in this paper.

\section{Data and parameterization}

The main model inputs are the supply of allowances in the EU ETS, the abatement cost parameters for the emitters, the hedging requirements of power firms, and risk return requirements of speculative investors.

For the supply of allowances into the EU ETS, we approximate the allocation of allowances as outlined in the European Commission Reference Case Scenario (EU, 2013), updated with 2012 data. The allocated allowances plus the import of offsets increased to $3 \mathrm{GtCO}_{2}$ in 2012 and will peak again in 2020 at $2.5 \mathrm{GtCO}_{2}$ when the back-loaded allowances are auctioned, decreasing at a linear reduction factor of $1.74 \%$ (EU, 2014b). ${ }^{5}$

The marginal abatement cost curve is derived from the ZEW PACE model (Landis, 2015). The PACE model is a Computable General Equilibrium Model, often applied for the European Commission to assess climate (and other) policy impacts. For the base case we use a linear Marginal Abatement Cost Curve (MACC) that approximates the PACE MACC around abatement levels according to the European Commission Reference Case. The intercepts and slopes of the marginal abatement cost curve are summarized in Table 2 . The sensitivity of the results to assumptions surrounding the MACC is also tested in Section 5.4.

\footnotetext{
${ }^{5}$ All permits stored in the New Entrants Reserve are assumed to be in the market by 2020.
} 
Table 2: Marginal abatement cost curve

\begin{tabular}{|c|c|c|c|c|}
\hline Year & Intercept & Slope & $\begin{array}{l}\text { Zero carbon price } \\
\text { emissions }\end{array}$ & $\begin{array}{c}\text { Reference carbon } \\
\text { price }\end{array}$ \\
\hline & $\mathrm{EUR} / \mathrm{tCO}_{2}$ & $\mathrm{EUR} /\left(\mathrm{GtCO}_{2} * \mathrm{tCO}_{2}\right)$ & $\mathrm{GtCO}_{2}$ & $\mathrm{EUR} / \mathrm{tCO}_{2}$ \\
\hline 2010 & $-\quad 2.65$ & 48.74 & 2.22 & 11 \\
\hline 2015 & - $\quad 1.80$ & 50.44 & 2.25 & 5 \\
\hline 2020 & $-\quad 3.45$ & 57.38 & 2.17 & 10 \\
\hline 2025 & 8.57 & 61.20 & 2.21 & 13 \\
\hline 2030 & - $\quad 32.21$ & 85.75 & 2.41 & 35 \\
\hline 2035 & - $\quad 66.31$ & 101.43 & 2.63 & 56 \\
\hline 2040 & - 111.54 & 103.70 & 3.12 & 78 \\
\hline 2045 & - $\quad 170.05$ & 96.77 & 3.81 & 90 \\
\hline 2050 & - 211.77 & 93.90 & 4.36 & 100 \\
\hline
\end{tabular}

Source: Landis (2015)

The hedgers' projected coal and natural gas power generation is taken from the Reference Scenario of the European Commission (EU, 2013). The carbon intensities of coal- and gas-fired plants are based on data from the IPCC (2006). If power firms hedge $100 \%$ of their projected generation in the years prior to production, then the 2014 hedging volume amounts to almost $1.2 \mathrm{GtCO}_{2}$. To account for power firms' flexibility to deviate from this hedging schedule, we assume that they adjust their hedging schedule by up to $20 \%$ if they expect carbon prices to deviate from a $3 \%$ growth rate (Schopp and Neuhoff, 2013). This results in a hedging corridor of 1-1.4 $\mathrm{GtCO}_{2}$ in 2014, declining with the shift from carbon intensive to renewable power generation, as outlined in the Reference Case Scenario (e.g. by 2020 to 0.8-1.2 $\mathrm{GtCO}_{2}$ ). This is in line with other studies (Point Carbon, 2014; Pöyry, 2013; Tschach Solutions, 2014). However, the assumption on the hedging schedule is uncertain, since data on power firms' hedging is only partially accessible and hedging needs can change over time with changes in the power demand, the carbon intensity of power production as well as power market design choices and other factors impacting contracting strategies. Results on a sensitivity analysis on the hedging schedule and the hedging flexibility are presented in Section 5.4.

Given typical risks in commodity markets and additional regulatory risk in carbon markets, speculators require a large risk premium before they bank allowances. Based on interviews with market participants and experience from other commodity markets, it is assumed that market participants bank allowances only if they expect annual price increases of $13 \%$ (real). This contrasts to an assumption for the social rate of discount of $r_{\text {social }}=3 \%$ (real).

\section{Results}

In this section, the impact of a limited capacity of market participants to bank emission permits at social discount rates on the EU ETS is quantified (5.1) before assessing the performance of quantity 
based (5.2) and price based (5.3) MSR designs. Table 3 summarizes the main results. The sensitivity of the results to key input parameters are assessed in Section 5.4 below.

Table 3: Performance indicators efficiency, robustness, price credibility, transformation

\begin{tabular}{|l|c|c|c|c|}
\hline & Efficiency & Price Credibility & Consistency & Robustness \\
\hline No Banking & $\mathbf{0 \%}$ & $\mathbf{0 \%}$ & $\mathbf{0 \%}$ & $\mathbf{0 \%}$ \\
\hline No MSR & $33 \%$ & $5 \%$ & $48 \%$ & $51 \%$ \\
\hline EC MSR & $68 \%$ & $23 \%$ & $58 \%$ & $83 \%$ \\
\hline Early Start MSR & $\mathbf{7 6 \%}$ & $\mathbf{2 8 \%}$ & $60 \%$ & $90 \%$ \\
\hline Low price based MSR & $50 \%$ & $14 \%$ & $53 \%$ & $60 \%$ \\
\hline High price based MSR & $\mathbf{8 1 \%}$ & $41 \%$ & $66 \%$ & $97 \%$ \\
\hline High Inj MSR & $96 \%$ & $37 \%$ & $57 \%$ & $100 \%$ \\
\hline Idealised conditions & $\mathbf{1 0 0 \%}$ & $\mathbf{1 0 0 \%}$ & $\mathbf{1 0 0 \%}$ & $\mathbf{1 0 0 \%}$ \\
\hline
\end{tabular}

Note: The results have been scaled linearly between $0 \%$ and $100 \% .100 \%$ performance reflects ideal banking conditions where the price path follows the social rate of discount. $0 \%$ performance reflects no inter-temporal optimisation.

\subsection{No market stability reserve}

In an idealized ETS without any regulatory or market failures, participants can bank unlimited volumes of surplus allowances at social discount rates. Hence, the carbon price trajectory evolves at the social rate of discount and firms smooth their abatement effort over time accordingly. Figure 1a illustrates that for our parametrization of the abatement cost curve, business as usual emission trajectory and emission cap, such an efficient banking strategy results in a privately held volume of surplus allowances increasing to $7 \mathrm{GtCO}_{2}$ by 2030. In 2030 the emission volume would match the annual emission cap and in the subsequent years banked allowances are used to accommodate for emissions exceeding the cap. As a second extreme, we assess an ETS without inter-temporal flexibility. Emissions in any one period may not exceed the annual cap. As a result both abatement effort and carbon prices are volatile as depicted in Figure $1 \mathrm{c}$ and $1 \mathrm{~d}$. In reality, most real world emission permit markets fit somewhere between these two extremes.

If firms' have some but limited flexibility to bank beyond hedging needs, the system has less flexibility to bring forward cost effective abatement and to smooth responses to shocks such as the economic crisis (Figure 1b). With an increase in the surplus, carbon prices decrease in the early periods, making it attractive for speculators to bank the unused allowances. However, they do so only at the rate of return required by speculative investors such that carbon prices increase steeply until the surplus has declined so it can be absorbed by firms for hedging purposes late in the 2030s. With lower carbon prices in the early periods, abatement is delayed to the later years resulting in higher prices in later years and a higher net present value of abatement costs. As such, a limited capacity to bank is diverting the EU ETS from the efficient abatement pathway. Furthermore, constrained banking at social discount rates results in a steeper price trajectory, therefore limiting price credibility. As the price trajectory is increasing more steeply (speculative returns) than the price increase at which future contracts are offered by arbitrageurs (3-5\%), also the price consistency is low. 


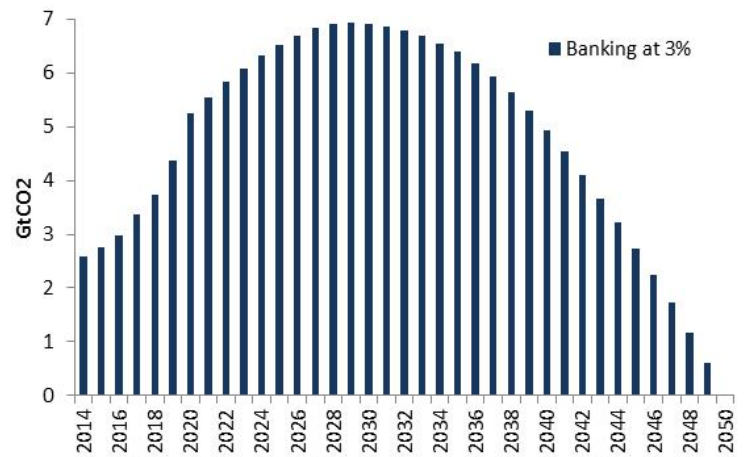

a. Banked volumes - perfect banking

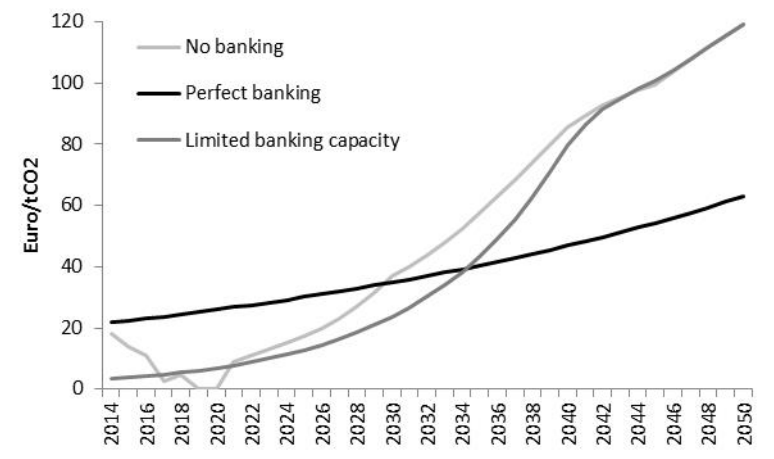

c. Carbon price

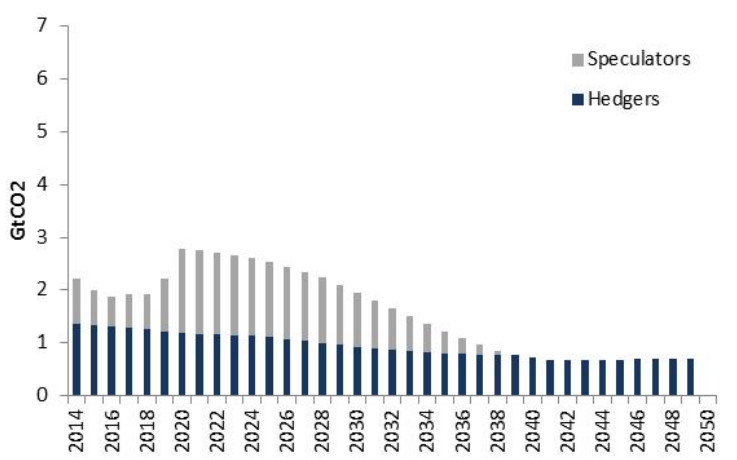

b. Banked volumes - limited banking capacity

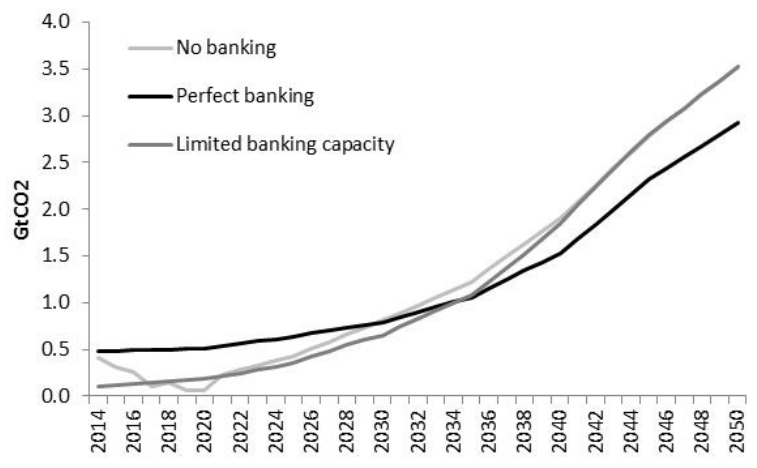

d. Abatement

Figure 1: Limited banking capacity

\subsection{Quantity based market stability reserves}

Three quantity based MSRs are tested: (i) The EC MSR as proposed by the European Commission; (ii) the Early Start MSR as proposed by the United Kingdom and Germany and (iii) the High Inj MSR as proposed by France.

Figure 2 demonstrates that the public banking of allowances through the EC MSR reduces the surplus, so that the demand by hedgers matches the remaining surplus post 2030 . By shifting the surplus into the hedging corridor, the market stability reserve avoids allowance banking by speculative investors at $13 \%$ discount rates in the 2030s. As a result the trajectory of the price curve is flatter than in the case of no MSR. This effect is improving price credibility and price consistency indicators by 18 and 10 percentage points, respectively. Thus, prices as well as abatement increase in the early periods. Prices remain high in the later periods, as the reserve carries $3 \mathrm{GtCO}_{2}$ beyond 2050 . Overall the EU ETS is closer to the efficient abatement pathway with the introduction of the EC MSR, reflected in an improvement to the efficiency criterion of $35 \%$. 


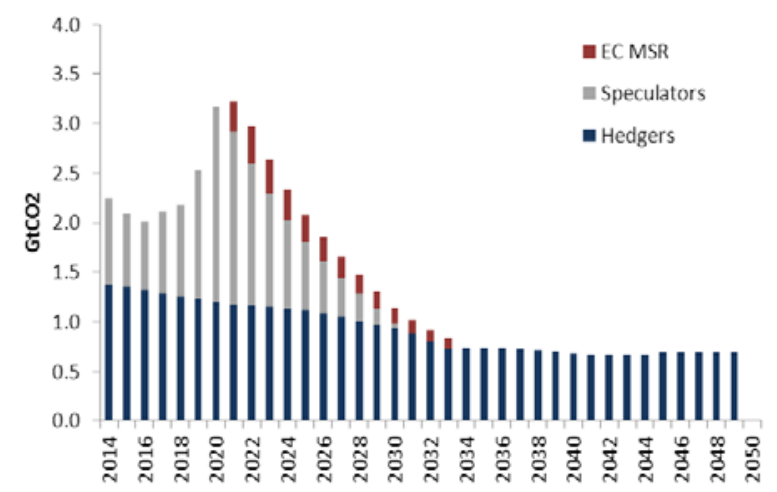

a. Banking volumes

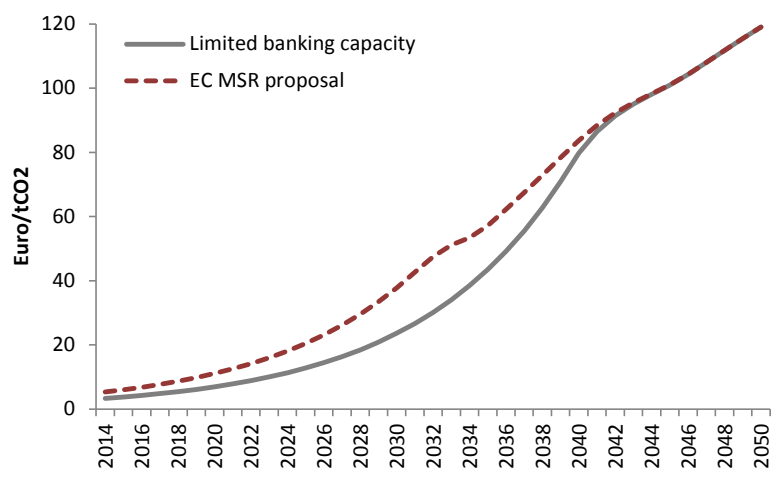

b. Carbon prices

Figure 2: EC Market Stability Reserve

The Early Start MSR is implemented in 2017 with the $0.9 \mathrm{GtCO}_{2}$ back-loaded allowances transferred directly into the reserve. Given the combination of a smaller surplus and quicker implementation of the reserve, the surplus reaches the hedging corridor five years earlier compared to the EC MSR, by 2025 (Figure 3a). This results in slightly higher prices and increased abatement in the early periods, when compared to the EC MSR (Figure 3b). These factors together result in an improvement to the EU ETS performance indicators when compared to the EC MSR. Specifically, efficiency is improved by $8 \%$; robustness by $7 \%$, price credibility by $5 \%$ and price consistency by $2 \%$.

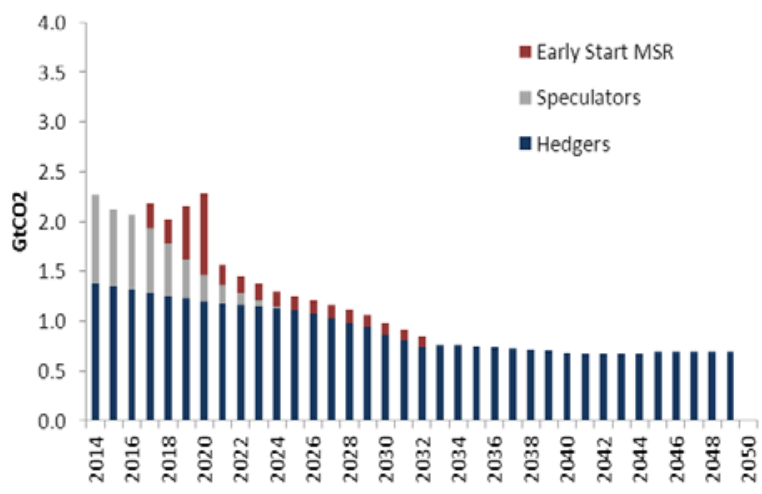

a. Banking volumes

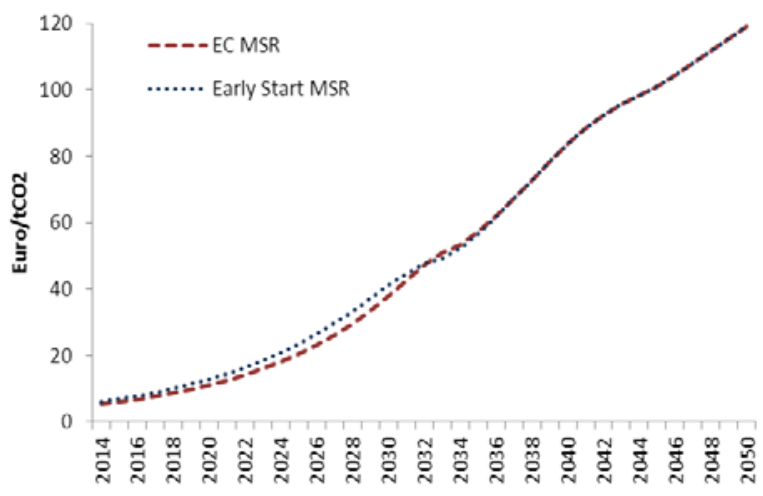

b. Carbon prices

Figure 3: Early Start Market Stability Reserve

With an increase in the response rate of the reserve to 33\% (as proposed by France), the market outcome gets more sensitive to the speed of the response as well as to the threshold levels. Figure 4 illustrates that the reserve shifts the surplus into the hedging corridor by 2022. As the reserve withdraws more allowances than any other tested, prices increase not only during the early periods, but also in the 2040s. Consequently, abatement over the considered period is also higher as some of the allowances are never released over the modeling period and as such the cap is tighter. 


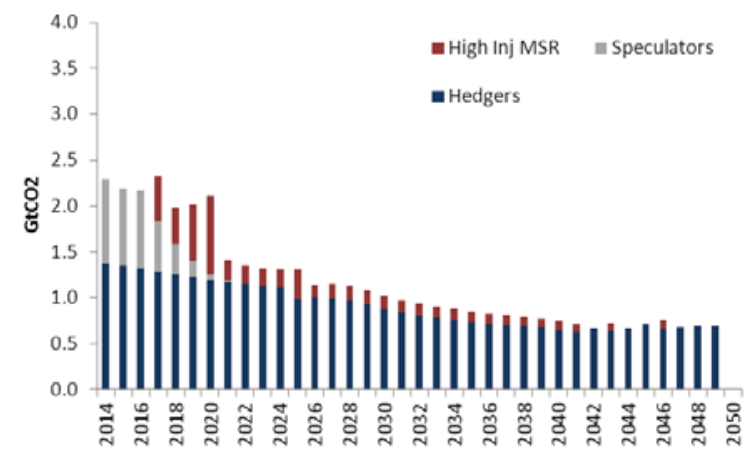

a. Banking volumes

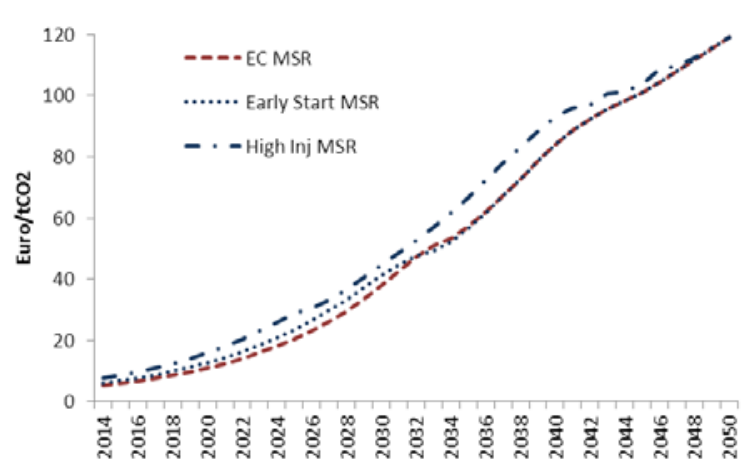

b. Carbon prices

Figure 4: High Inj Market Stability Reserve

\section{Additional Design Considerations}

To examine how the MSRs accommodate shocks, we compare how the different design options respond to a negative economic shock from 2030 to 2034. To focus the comparison on the response to the shock we assume the same starting point in terms of allowances in circulation and reserve volume for the year 2029. Then we consider three different design options for the reserve in addition to the EC MSR: an increase in the speed of the response to one year, an additional increase in the response rate to fill the reserve to $20 \%$, and a response proportional to $33 \%$ of the difference to lower threshold levels (as in the High Inj MSR). All reserves design choices respond to the shock and bank some of the additional allowances that become available (Figure $5 \mathrm{a}$ ). As a result the price in the years after the shock only fall by half the level that would be observed without the reserve in place and recovers earlier to the trajectory that would be observed without a shock (Figure 5b). Overall we find that an MSR does improve robustness, but we do not identify alternative parametrizations of the MSR which outperform the European Commission proposed MSR.

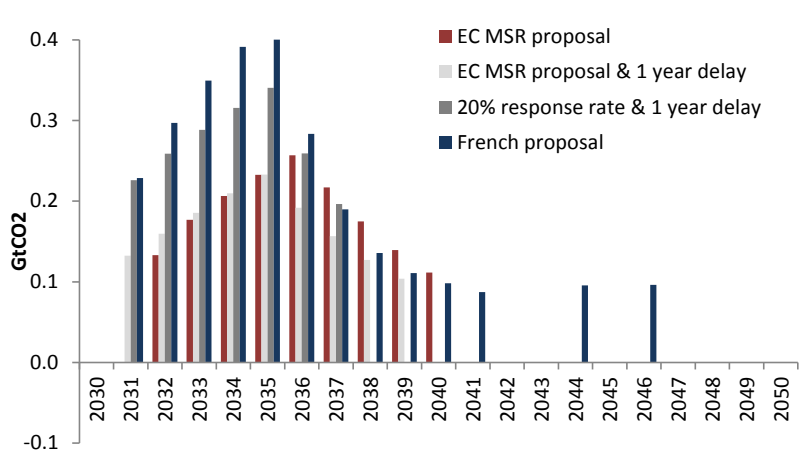

a. Annual withdrawal and injection of reserve

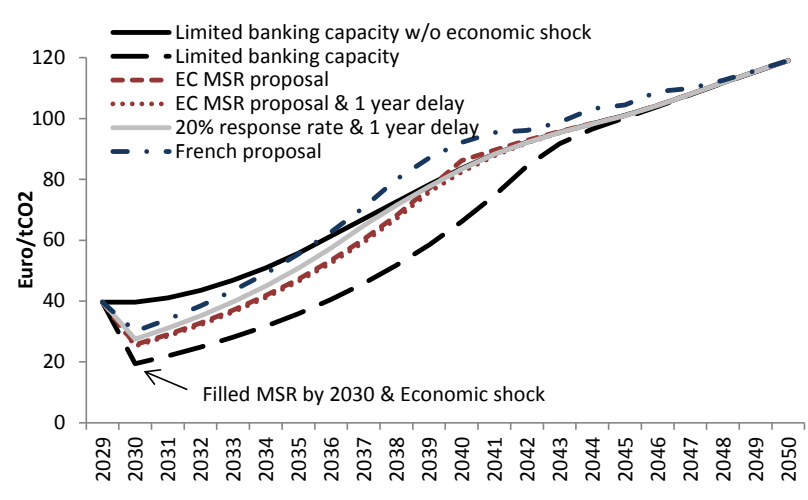

b. Carbon prices

Figure 5: Response of reserves to economic shock

\subsection{Price based market stability reserves}

Price based reserves have also been considered or implemented in Australia, Asia and North America. To assess a price based reserve for the EU ETS, we consider two levels of reserve prices for auctions: 10 Euro and 20 Euro in 2021, both increasing at 5\% each year. 
With a reserve price of $10 \mathrm{EUR} / \mathrm{tCO}_{2}$ the carbon price stays close to the floor rather than converging towards a dynamically efficient trajectory. As such, the low price floor does not result in significant improvements of the performance indicators.

The higher reserve price trigger of $20 \mathrm{EUR} / \mathrm{tCO}_{2}$ for 2021 is close to the price level in the optimal banking scenario (see Figure 1). ${ }^{6}$ At this price level allowances exceeding hedging demand are transferred into the MSR. Subsequently, the allowances volume is within the hedging corridor and a relatively flat forward curve is followed until the surplus is gradually increasing again compared to hedging needs and thus the forward curve is steeper. In our parametrization - with sufficient scarcity in later years - the price based MSR is not triggered again. This matches the results observed in the experimental study by Holt and Shobe (2015). They find that a price based reserve may only be triggered for a few years with subsequent price trajectories again deviating above the reserve price level. Compared to the EC MSR proposal - the price level is initially higher and then post 2029 lower. With a well calibrated reserve price, the abatement profile is similar to that of the efficient abatement pathway and the best performance of all MSR designs can be achieved across the performance indicators (See Table 3).

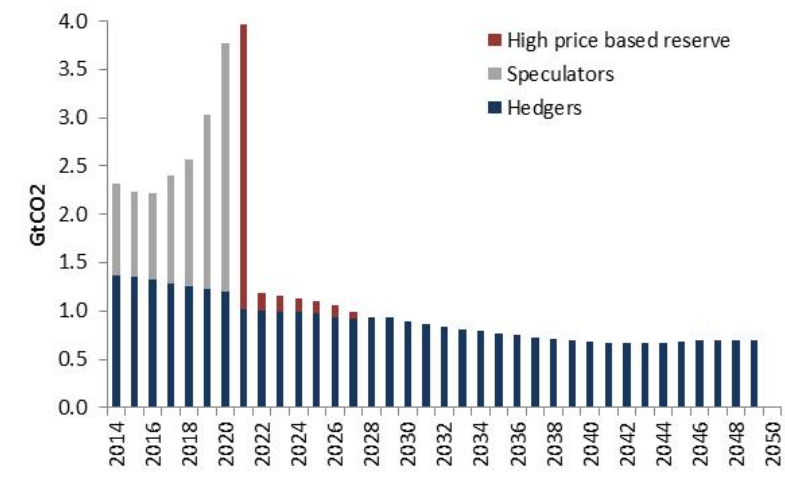

a. Banking volumes (High price collar)

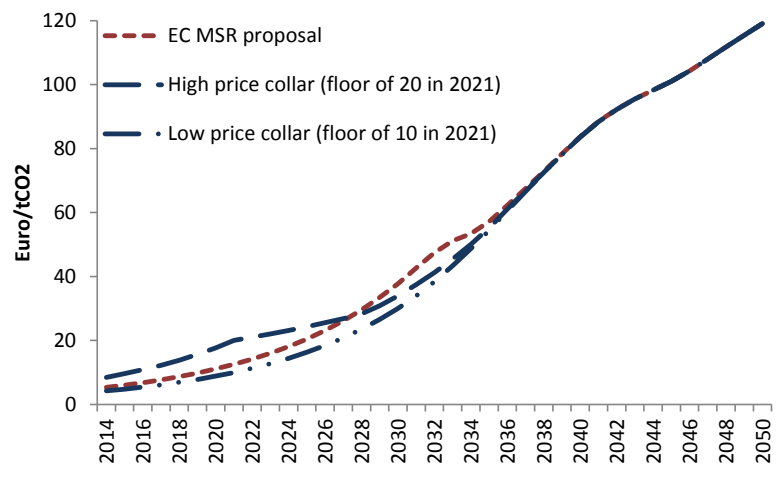

b. Carbon prices

Figure 6: Price based reserves

However, good performance of a price based MSR is subject to the capacity of scientists to determine the correct reserve price level in a world of asymmetric information and uncertainty on economic and technological development and costs. Furthermore, even if such a price level could be calculated, in the European context it is also anticipated that the reserve price level that would emerge as compromise between discussions between EU Commission, EU Parliament and EU Member states would deviate significantly from such an analytically determined price level.

\subsection{Sensitivity to key assumptions}

The relative performance of the MSRs is tested against assumptions surrounding the hedging schedule, MACCs and technological development. The ranking of the MSRs are largely robust to the input assumptions.

\footnotetext{
${ }^{6}$ In our simple model, we implement the reserve price in auctions as a price floors (e.g. transfer of allowances in 2021 until price is at or above trigger price. In practice the transfer volume of allowances into an MSR with reserve price in auctions limited by the auction volume. Thus, the fill up would be spread out over 3 years.
} 


\section{Sensitivity to hedging schedule}

Given the importance of the hedging demand to the MSR design, the performance of the MSRs are tested given changes to the hedging strategy and resulting hedging schedule. Figure 7a shows that for the Early Start MSR ${ }^{7}$ with fixed threshold levels, a higher hedging schedule results in a higher carbon price path. This results from the combination of two effects. First, the difference between allowances in circulation and hedging demand is small, and thus in the years up to 2029 the forward curve is flatter. Second, the trigger levels for the MSR better match the hedging demand post 2030 (due to declining carbon intensity of power generation hedging demand declines). Hence, post 2030 the carbon price trajectory for the higher hedging demand is smoother.

Interviews with power firms pointed to some flexibility to adjust the hedging volume, so as to arbitrage price differentials between carbon prices anticipated in the firm and the forward price for carbon. For example, if carbon prices are anticipated to increase more steeply than reflected in the forward curve, the hedging volume is increased by up to $20 \%$ (Schopp and Neuhoff, 2013). We tested the response to changes of this assumption - e.g. an increase in the flexibility from $20 \%$ to $40 \%$ and a reduction from $20 \%$ to $1 \%$. We find that changes in the hedging flexibility do not strongly affect the ability of the reserve to absorb an economic shock.

Our analysis indicates that MSR designs are sensitive to the hedging schedule. Hedging needs will change over time with changes in the power demand, the carbon intensity of power production as well as forward contracting strategies. Therefore, any quantity based MSR will need to be updated to reflect changes in the hedging schedule. The new Regulation on Wholesale Energy Market Integrity and Transparency (REMIT) will provide data on forward contracts and can thus inform the setting of the quantity thresholds.

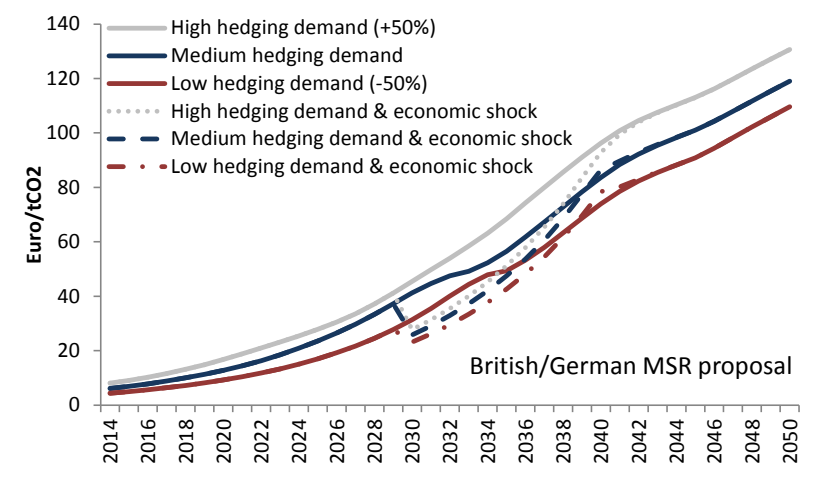

a. Changes in hedging schedule

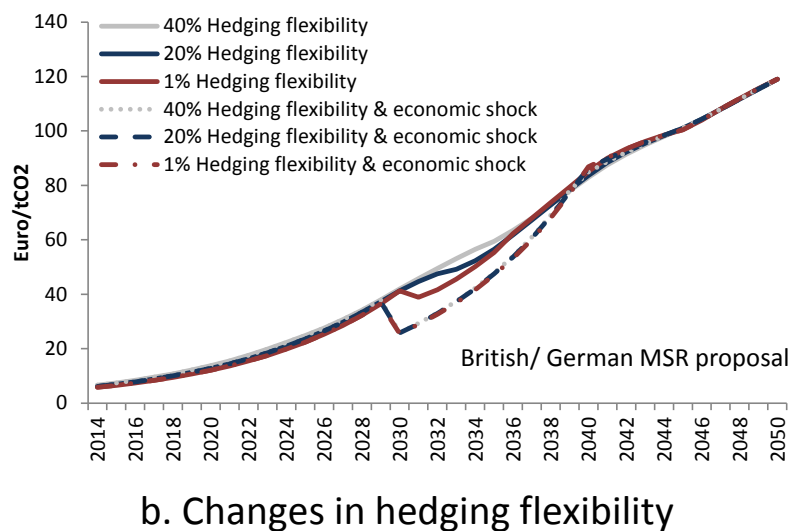

b. Changes in hedging flexibility

Figure 7: Carbon prices for different hedging parametrizations

\section{Sensitivity to technology cost assumptions}

In addition, we assess the robustness of the results to assumptions on the MACC. We run scenarios for a lower linear MACC and a higher quadratic MACC derived from the PACE model (see Section 4). Table 4 illustrates that across most indicators, the ranking of the reserve designs remains similar. One significant difference is that the price based MSR (starting at $€ 10 / \mathrm{tCO}_{2}$ in 2021) performs better if

\footnotetext{
${ }^{7}$ To limit the number of scenarios presented, sensitivity analysis of the hedging schedule is limited to the Early Start MSR. The Early Start MSR was selected as it approaches the hedging corridor quicker when compared to the EC MSR.
} 
abatement costs are lower. In this case the low trigger level more closely matches the optimal abatement pathway.

We also test whether the results are robust, if technology costs are endogenously determined in the model. Rather than assuming exogenously provided technology costs in the MACC, we model a simplified version of learning by doing: mitigation costs decline with increasing experience in abatement technologies. We scale abatement cost in the period post 2030 in proportion to the abatement effort before 2030 as compared to a case where no inter temporal smoothing takes place $\left(y_{t, n b}\right.$ and $\left.x_{t, n b}\right)$. The MACC is scaled by $f=\sum_{t=2015}^{2029} \frac{1}{15} \frac{y_{t}-x_{t}}{y_{t, n b}-x_{t, n b}}$ and the emitter's optimality conditions for the years post 2030 changes to:

$$
0 \leq \beta^{t-1}\left[-p_{t}+\vartheta_{t} f+x_{t} m_{t} f\right] \perp x_{t} \geq 0 \quad t \geq 2030
$$

With endogenous technological learning, additional early mitigation action reduces later mitigation costs and can thus reduce overall abatement cost. We again test the performance of the EU ETS without an MSR and with MSRs with different design choices. The relative performance of the reserves remains the same in the presence of endogenous technological learning. The absolute performance criteria also largely remain unchanged, with one important difference: if technological learning is modelled, an earlier start of the MSR results in additional abatement in the early years and triggers additional learning and thus results in a larger reduction of overall abatement costs and larger efficiency improvement.

Table 4: Performance of reserves with different MACC assumptions across key criteria

\begin{tabular}{|c|c|c|c|c|}
\hline \multicolumn{5}{|c|}{ Price } \\
\hline & $\begin{array}{c}\text { Efficiency } \\
\text { (\%) }\end{array}$ & $\begin{array}{c}\text { Credibility } \\
\text { (\%) }\end{array}$ & $\begin{array}{c}\text { Consistency } \\
\text { (\%) }\end{array}$ & $\begin{array}{c}\text { Robustness } \\
\text { (\%) }\end{array}$ \\
\hline \multicolumn{5}{|c|}{ Base Case } \\
\hline No MSR & 33 & 5 & 48 & 51 \\
\hline EC MSR & 68 & 23 & 58 & 83 \\
\hline Early Start MSR & 76 & 28 & 60 & 90 \\
\hline Price Based MSR (Low) & 50 & 14 & 53 & 60 \\
\hline \multicolumn{5}{|c|}{ High Cost Technology MACC } \\
\hline No MSR & 52 & 13 & 44 & 59 \\
\hline EC MSR & 90 & 28 & 53 & 96 \\
\hline Early Start MSR & 92 & 29 & 54 & 98 \\
\hline Price Based MSR (Low) & 53 & 14 & 44 & 60 \\
\hline \multicolumn{5}{|c|}{ Low Cost Technology MACC } \\
\hline No MSR & 33 & 5 & 48 & 51 \\
\hline EC MSR & 68 & 23 & 58 & 83 \\
\hline Early Start MSR & 76 & 28 & 60 & 89 \\
\hline Price Based MSR (Low) & 70 & 34 & 62 & 82 \\
\hline \multicolumn{5}{|c|}{ With Endogenous Technological Learning } \\
\hline No MSR & 33 & 5 & 48 & 48 \\
\hline EC MSR & 71 & 23 & 58 & 80 \\
\hline Early Start MSR & 94 & 30 & 61 & 90 \\
\hline Price Based MSR (Low) & 50 & 14 & 53 & 57 \\
\hline
\end{tabular}




\section{Conclusion}

This paper examined whether and how an MSR can improve the functioning of the EU ETS using a dynamic, deterministic partial equilibrium framework. The model represents different types of actors banking emission allowances, so as to depict the effect of market and regulatory failures as well as institutional constraints on emission permit markets. Once the surplus exceeds hedging needs by market participants, prices need to decline until they can support steep price increases in subsequent years that attract speculative investors with high risk return requirements.

With this modelling framework the performance of different design choices of an MSR is assessed, including proposals by the European Commission, Germany/United Kingdom and France. We also explore possible design options of a price based MSR that has been implemented in emission trading mechanisms outside of Europe.

The modeling results show both quantity and price based MSRs could improve the functioning of the market but each faces challenges. The quantity based MSR proposed by the European Commission moves the EU ETS closer the efficient abatement pathway and improves performance of EU ETS on performance indicators including price credibility and consistency as well as robustness to shocks. An earlier start of the MSR with the back-loaded allowances placed directly into the reserve yields further improvements on these indicators. Specifically, not returning the back-loaded allowances to the market reduces price variance and improves price credibility and consistency for investors.

The performance of a price based MSR can be very high if the reserve price can be set to match price levels on the optimal abatement pathway. However, due to economic and technological uncertainty it is difficult to determine this price level ex-ante. Furthermore, with the need to agree on a price among European Commission, European Parliament and European Union Member States it could be difficult to implement appropriately determined price. If as a result the reserve price is set too low, only a very limited improvement of the performance indicators is achieved.

The performance of a quantity based MSR is robust to changes in the marginal abatement cost curve and improves if dynamic effects resulting from endogenous technological learning are considered. However, the level of hedging demand for allowances may change over time and needs to be reflected in the trigger levels of a quantity based MSR. Our analysis suggests that trigger levels could be updated based on empirical data on power demand, carbon intensity and energy contracting volumes. 


\section{References}

Bailey, R.E., 2005. The Economics of Financial Markets. Cambridge University Press.

Baldursson, F.M., Von der Fehr, N.-H.M., 2004. Price volatility and risk exposure: on market-based environmental policy instruments. Journal of Environmental Economics and Management 48, 682704.

Bessembinder, H., 1992. Systematic risk, hedging pressure, and risk premiums in futures markets. Review of Financial Studies 5, 637-667.

Betz, R., Cludius. J., Schopp, A. 2015. The role of the financial sector in European Union Emission Trading. Unpublished Manuscript.

Chevallier, J., 2012. Banking and borrowing in the EU ETS: A review of economic modelling, current provisions and prospects for future design. Journal of Economic Surveys 26, 157-176.

Clò, S., Battles, S., Zoppoli, P., 2013. Policy options to improve the effectiveness of the EU emissions trading system: A multi-criteria analysis. Energy Policy 57, 477-490.

DGEC, 2014. Non-Paper - French Position on the Commission's proposal to establish a Market Stability Reserve. La Direction générale de l'énergie et du climat, Paris.

EEX, 2012. German Baseload Year Futures, NCG Natural Gas Year Futures, ARA Coal Year Futures.

EU, 2013. EU Energy, transport and GHG emissions, trends to 2050, reference scenario 2013. European Commission, Brussels.

EU, 2014a. Conclusions of European Council (23 and 24 October 2014). 2030 Climate and Energy Policy Framework. EUCO 169/14. European Council, Brussels.

EU, 2014b. Proposal for a Decision of the European Parliament and of the Council concerning the establishment and operation of a market stability reserve for the Union greenhouse gas emission trading scheme and amending Directive 2003/87/EC, COM(2014) 20 /2. European Commission, Brussels.

Fell, H. 2015. Comparing Policies to Confront Permit Over-allocation. Unpublished Manuscript.

Fell, H., Morgenstern, R.D., 2010. Alternative approaches to cost containment in a cap-and-trade system. Environmental and Resource Economics 47, 275-297.

Holt, C., Shobe, W. 2015. Price and quantity-based "collars" for stabilizing emissions allowance prices: An experimental analysis. Unpublished working paper.

IPCC, 2006. IPCC Emissions Factor Database. Intergovernmental Panel on Climate Change, Geneva. 
Landis, F., 2015. Final report on marginal abatement cost curves for the evaluation of the Market Stability Reserve. ZEW Working Paper Documentation Nr. 15-01.

Neuhoff, K., Acworth, W., Betz, R., Burtraw, D., Cludius, J., Fell, H., Hepburn, C., Holt, C., Jotzo, F., Kollenberg, S., Landis, F., Salant, S., Schopp, A., Shobe, W., Taschini, L., Trotignon, R., 2015. Is a Market Stability Reserve likely to improve the functioning of the EU ETS? Evidence from a model comparison exercise. Climate Strategies, London.

Neuhoff, K., Schopp, A., Boyd, R., Stelmakh, K., Vasa, A., 2012. Banking of surplus emissions allowances: Does the volume matter? Discussion Paper 1196. German Institute for Economic Research, Berlin.

Point Carbon, 2014. The MSR: Ceiling and floor triggers: CEPS Task force: EU ETS Market Stability Reserve. Point Carbon, Brussels.

Pöyry, 2013. Assessment of the allowance supply adjustment mechanism. A report to Fortum Pöyry Management Consulting, Vantaa.

Rubin, J.D., 1996. A model of intertemporal emission trading, banking, and borrowing. Journal of Environmental Economics and Management 31, 269-286.

Schopp, A., Neuhoff, K., 2013. The Role of Hedging for Carbon Markets. DIW Discussion Papers 1271. German Institute for Economic Research, Berlin.

Stavins, R.N., 1995. Transaction costs and tradeable permits. Journal of environmental economics and management 29, 133-148.

Stranlund, J.K., Murphy, J.J., Spraggon, J.M., 2014. Price controls and banking in emissions trading: An experimental evaluation. Journal of Environmental Economics and Management 68, 71-86.

Taschini, L., Kollenberg, S., Duffy, C., 2014. System responsiveness and the European Union Emissions Trading System. Policy paper, Grantham Research Institute.

Tschach Solutions, 2014. Expected market impact of the proposed MSR. Tschach Solutions, Karlsruhe.

Wang, C., 2001. Investor sentiment and return predictability in agricultural futures markets. Journal of Futures Markets 21, 929-952. 